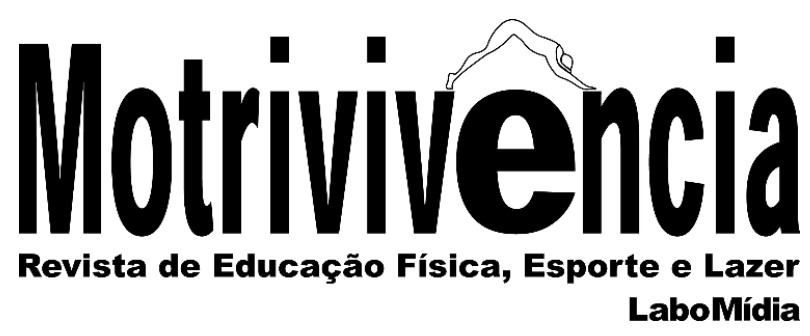

\title{
A produção da Educação Física brasileira sobre fair play e racismo no esporte: estado da arte de teses e dissertações
}

\section{RESUMO}

Fair Play (FP) refere-se a atitudes moralmente boas na prática esportiva e reprova o racismo. No Brasil, o esporte começou a se desenvolver após o fím da escravidão, de modo que o racismo acompanha a sua história. A pesquisa teve por objetivo mapear e analisar a produção acadêmica da Educação Física brasileira sobre a temática do $\mathrm{FP}$ e do racismo no esporte. Realizou-se revisão bibliográfica das teses e dissertações produzidas nos principais Programas de Pós-Graduação de Educação Física brasileiros. Levantaram-se 32 teses e 103 dissertações, das quais cinco teses e dez dissertações foram analisadas. Essa considerável redução ocorreu porque poucos trabalhos relacionam diretamente as duas temáticas. Entre os analisados, destacaram-se aqueles que abordaram o fenômeno esportivo a partir da perspectiva do racismo estrutural, em modalidades como futebol, capoeira e boxe. Houve também expressiva parcela que realçou a importância do FP e do combate ao racismo na Educação Física escolar.

PALAVRAS-CHAVE: Espírito esportivo; Racismo; Esportes; Educação física; Brasil
João Vitor Busquim Braga

Discente em Educação Física

Universidade Estadual de Londrina-UEL

Centro de Educação Física e Esporte

Londrina, Paraná, Brasil

(in memorian)

Kevin Keiti Oshima

Discente em Educação Física

Universidade Estadual de Londrina-UEL

Centro de Educação Física e Esporte

Londrina, Paraná, Brasil

kevinoshimak@gmail.com

(D) https://orcid.org/0000-0002-3762-2001

André Dalben

Doutor em Educação

Universidade Estadual de Londrina-UEL

Centro de Educação Física e Esporte

Londrina, Paraná, Brasil andredalben@yahoo.com.br

https://orcid.org/0000-0003-1689-6238 


\title{
Brazilian Physical Education literature about fair play and racism in sports: state of the art of thesis and dissertations
}

\begin{abstract}
Fair Play (FP) refers to morally good attitudes in sporting practices and the rejection of racism. In Brazil sports started to develop after the end of slavery, and racism followed its history. The purpose of this research is to map and analyze the Brazilian Physical Education literature about FP and racism in sports. A bibliographic review of thesis and dissertations from the main postgraduation programs of the country was carried out. Thirty-two thesis and 103 dissertations were found; five theses and ten dissertations were analyzed. This large reduction happened because only a few related directly to both issues. Among the analyzed work, those that approach sports from the perspective of structural racism in practices such as football, capoeira and boxing stand out. There was also a significant amount of studies that highlight the importance of FP and the fight against racism in school Physical Education.
\end{abstract}

KEYWORDS: Fair play; Racism; Sport; Physical education; Brazil

\section{La producción de la Educación Física brasileña sobre fair play y racismo en el deporte: estado del arte de tesis y disertaciones}

\section{RESUMEN}

Fair Play (FP) se refiere a actitudes moralmente buenas en la práctica deportiva y rechaza al racismo. En Brasil, el deporte comenzó a desarrollarse después del fin de la esclavitud, y el racismo acompaña su historia. El objetivo de la investigación es mapear y analizar la producción académica de la Educación Física brasileña sobre la temática del FP y del racismo en el deporte. Se realizó una revisión bibliográfica de las tesis y disertaciones producidas en los principales programas de posgrado de Educación Física brasileños. Fueron recopiladas 32 tesis y 103 disertaciones, de las cuales 5 tesis y 10 disertaciones fueron analizadas. Esta significativa reducción ocurrió porque pocos trabajos tienen relación directa con las dos temáticas. Entre los analizados, se destacan aquellos que abordan el fenómeno deportivo desde la perspectiva del racismo estructural, en modalidades como fútbol, capoeira y boxeo. Hubo también una cantidad importante de investigaciones que destacan la importancia del FP y de la lucha contra el racismo en la Educación Física escolar.

PALABRAS-CLAVE: Juego limpio; Racismo; Deportes; Educación física; Brasil 


\section{INTRODUÇÃO}

No início do esporte moderno, na Inglaterra do século XIX, foram configurados uma série de valores atrelados à competição honesta e ao respeito mútuo entre os adversários. Tratava-se do desenvolvimento de uma ética burguesa e aristocrática relacionada ao mundo do esporte amador, que teve como principal local de desenvolvimento as universidades. $\mathrm{O}$ esporte foi concebido como uma prática educativa de formação do caráter, que tinha na figura do gentleman sua principal referência, como uma forma de desenvolver a audácia, resistência, autocontrole e honra entre os membros da burguesia e da aristocracia que frequentavam a instituição universitária naquele momento (GAY, 1995; VIGARELLO; HOLT, 2008).

Estes foram os primeiros anos de vida do conceito que hoje a população mundial conhece pelo nome de Fair Play (Jogo Limpo ou Jogo Justo, em tradução livre - FP). O FP pode ser definindo mais especificamente como um conjunto de atitudes moralmente boas dentro da prática esportiva (TAVARES, 2014). Muito embora a noção de FP já estivesse presente no advento do esporte moderno, a sua conceituação e propagação é bem mais recente. Enquanto o esporte se difundiu pelo mundo ainda no fim do século XIX, o conceito de FP foi discutido em nível internacional pela primeira vez em 1963. Em decorrência dos inúmeros acontecimentos e comportamentos perigosos em competições oficiais, pela primeira vez foi realizado um seminário, organizado pela UNESCO, pela Associação Internacional de Imprensa Esportiva e pelo Conselho Internacional de Esporte e Educação Física, para tratar sobre o tema (SANTOS, 2005).

Hoje em dia, o panorama geral é um pouco contraditório. Por um lado, o FP se consolidou como um código de ética do esporte, preconizando o respeito, a honestidade, a igualdade, a amizade, a integridade, a tolerância, a excelência, dentre outras muitas características que, inclusive, já foram redigidas por organizações e comitês internacionais (SANTOS, 2005). Por outro lado, o esporte se consolidou na atualidade como um expressivo setor econômico, sendo governado e direcionado de acordo com interesses de grandes empresas e corporações, o que leva à moção de montantes financeiros elevados e ao estímulo à atitudes nem sempre éticas por parte de dirigentes esportivos e jogadores. O resultado muitas vezes é um descaso real com todas as características que deveriam assegurar um ambiente saudável e agregador (MEINBERG, 2007).

$\mathrm{Na}$ imprensa abundam relatos atualmente de casos de racismo no mundo esportivo, geralmente como uma forma de desestabilizar emocional e psicologicamente os atletas de diversas modalidades. Um dos temas mais evidentes dentro do FP é o racismo, que pode ser compreendido como um conjunto de ideias que hierarquiza características naturais e culturais das diferentes 
sociedades humanas, de modo a permitir que uma coletividade, interpretada como inferior, seja discriminada a partir das práticas de outra, designada como superior (ZUBAIDA, 1996). Visto o perigo que representam tais crenças, que serviram como base para a investida nazista iniciada na década de 1930, por exemplo, o Movimento Olímpico deixa bem clara sua posição: “Toda e qualquer forma de discriminação relativamente a um país ou a uma pessoa com base na raça, religião, política, sexo ou outra é incompatível com a pertença ao Movimento Olímpico" (COMITÊ OLÍMPICO INTERNACIONAL, 2011). Tal posição se alinha ao segundo artigo da Declaração Universal dos Direitos Humanos (ORGANIZAÇÃO DAS NAÇÕES UNIDAS, 1948), o qual institui que os direitos e liberdades individuais não podem sofrer distinção alguma, de raça, cor, sexo, língua, religião, opinião política ou outra, origem nacional ou social, fortuna, nascimento ou outro estatuto. $\mathrm{O}$ racismo, entretanto, acompanha toda a trajetória da humanidade desde as primeiras civilizações, pela escravização de povos considerados inferiores, até ocasiões mais recentes, na forma de inúmeros genocídios de grupos específicos com as mesmas justificativas etnocêntricas usadas antigamente.

O racismo teve influências em várias áreas da sociedade, acompanhando inclusive todo o desenvolvimento do esporte moderno nos últimos séculos. No Brasil, o racismo perdurou durante todo o período colonial, na forma do regime escravocrata, e, mesmo após a abolição de tal prática, não houve uma real inserção dos negros na sociedade, de modo que até nos dias de hoje são observados reflexos de tal situação (SKIDMORE, 2012; FERNANDES, 2008). Em virtude disso, sabendo que o esporte começou a se desenvolver no Brasil concomitantemente ao fim da escravidão, na segunda metade do século XIX (GOIS JÚNIOR, 2013), nota-se que o racismo acompanhou a história esportiva nacional, se fazendo presente até os dias atuais (SOUZA, 2014).

A partir da relação entre FP, racismo e esporte, a presente pesquisa propôs uma revisão bibliográfica da produção da área da Educação Física brasileira sobre os temas do FP e do racismo. Ao se partir do pressuposto de que a produção de conhecimento sobre um determinado tema é uma construção coletiva da comunidade científica, torna-se imprescindível a compreensão do que já fora produzido até o presente momento sobre determinados temas para o avanço do conhecimento. A pesquisa se justifica, assim, como uma contribuição para estudos futuros que abordam a ausência ou presença de atitudes éticas na prática esportiva, discussão cada vez mais presentes na nossa sociedade. Uma outra justificativa diz respeito a contribuição que a pesquisa poderá oferecer à prática docente de nível superior, pois ao mapear as principais pesquisas produzidas sobre o racismo e o esporte, o material levantado pode ser utilizado na formação profissional de futuros técnicos e dirigentes esportivos, assim como de professores de educação física escolar. 
A pesquisa teve por objetivos mapear e analisar a produção acadêmica da Educação Física brasileira em teses e dissertações sobre a temática do FP e do Racismo no Esporte. A sua motivação inicial esteve relacionada aos trabalhos desenvolvidos na disciplina Ser Humano e Sociedade, ofertada no curso de Bacharelado em Educação Física da Universidade Estadual de Londrina em 2017, e se configurou posteriormente como uma investigação na modalidade de Iniciação Científica.

\section{METODOLOGIA}

O estudo consistiu em uma revisão bibliográfica de publicações no formato de teses e dissertações (MARCONI; LAKATOS, 2003), para posterior análises quantitativa e qualitativa (PRODANOV; FREITAS, 2013). A pesquisa se insere, de forma mais ampla, entre aquelas denominadas como Estado do Conhecimento ou Estado da Arte de um determinado tema, ou seja, de caráter inventariante e descritivo da produção acadêmica. De acordo com Ferreira (2002), as pesquisas desse tipo são geralmente divididas em dois momentos. Um primeiro no qual o pesquisador "interage com a produção acadêmica através da quantificação e de identificação de dados bibliográficos, com o objetivo de mapear essa produção num período delimitado, em anos, locais, áreas de produção" (Ferreira, 2002, p. 265). Trata-se sobretudo das análises quantitativas que esse tipo de pesquisa permite realizar. O segundo momento se caracteriza pela "possibilidade de inventariar essa produção, imaginando tendências, ênfases, escolhas metodológicas e teóricas, aproximando ou diferenciando trabalhos entre si, na escrita de uma história de uma determinada área do conhecimento" (FERREIRA, 2002, p. 265). Trata-se sobretudo das análises qualitativas e historiográficas que esse tipo de pesquisa permite realizar.

$\mathrm{O}$ conjunto de teses e dissertações levantado pela pesquisa se limitou àquelas produzidas nos Programas de Pós-Graduação de Educação Física brasileiros com melhores notas na última avaliação quadrienal (2012-2016) da Coordenação de Aperfeiçoamento de Pessoal de Nível Superior (CAPES): Universidade de São Paulo (USP), Universidade Federal do Paraná (UFPR), Universidade Federal do Rio Grande do Sul (UFRGS), Universidade Federal de Santa Catarina (UFSC), Universidade Federal de Viçosa (UFV), Universidade Estadual de São Paulo - Rio Claro (UNESP-RC) e Universidade Federal de Minas Gerais (UFMG). Tais trabalhos acadêmicos foram levantados nas bibliotecas digitais das universidades em questão, exclusivamente dentro dos Programas de Educação Física e Esporte, utilizando os seguintes termos: "fair play", "jogo limpo", "espírito esportivo" e "racismo". 
A partir das pesquisas realizadas para cada termo nas bibliotecas digitais, uma primeira triagem foi realizada empregando os títulos das teses e dissertações encontradas. Essa triagem visou averiguar quais trabalhos poderiam ter relação direta com as temáticas exploradas pelo presente estudo. Após a primeira triagem, cada uma das teses e dissertações selecionadas foi analisada seguindo três de passos de aprofundamento da leitura, a saber: 1) leitura do Resumo e da Introdução; 2) leitura dos capítulos que estivessem relacionados com o tema a partir da consulta ao índice do trabalho acadêmico; 3) busca textual pelo documento dos termos empregados nas consultas às bibliotecas digitais e leitura dos parágrafos correspondentes. Tal procedimento se justifica devido ao número expressivo de teses e dissertações encontradas nas bibliotecas digitais e por considerarmos que a leitura apenas do resumo das teses e dissertações poderia não ser suficiente para a devida seleção daquelas que apresentavam maior afinidade com o presente estudo (FERREIRA, 2002). Para cada uma das teses e dissertações foi realizado um fichamento, o qual abrangeu: a) dados bibliográficos do material analisado; b) palavras-chave das teses e dissertações; c) citações importantes relacionadas à temática; d) resenha crítica. Por fim, com todas as fichas devidamente preenchidas, foi realizada uma segunda seleção das teses e dissertações que apresentaram maior afinidade com o presente estudo.

\section{RESULTADOS E DISCUSSÃO}

\section{Análises Quantitativas}

O Programa de Pós-Graduação de Educação Física da USP possui atualmente a maior nota na CAPES e dentro de sua biblioteca digital de teses e dissertações ${ }^{1}$ foram pesquisados os trabalhos para as áreas de Biodinâmica do Movimento Humano, Estudos do Esporte, Estudos Socioculturais e Comportamentais da Educação Física e do Esporte, e Pedagogia do Movimento Humano. No entanto, para nenhuma das palavras-chave pesquisadas foi encontrado qualquer resultado. Optamos, assim, por realizar uma busca mais ampla em todo o acervo da biblioteca digital. É importante relatar que houve algumas dificuldades em se utilizar a plataforma, como, por exemplo, a impossibilidade de se acessar mais do que dez páginas de resultados mostradas inicialmente, assim como a repetição do mesmo trabalho duas ou três vezes. Mesmo diante destes fatos, continuou-se a busca pelas teses e dissertações e foram obtidos os seguintes resultados: para a palavra-chave "fair play" foram selecionados sete trabalhos de um total 111 apresentados; para "jogo limpo" nenhum trabalho inédito se apresentou relevante de um total de 51 apresentados; para "espírito esportivo",

\footnotetext{
${ }^{1}$ https://www.teses.usp.br
} 
dois trabalhos foram elegidos de 40 apresentados; e, por fim, para "racismo", apenas um foi eleito na primeira triagem dos resultado de 83 apresentados. Portanto, totalizou-se dez trabalhos da USP, dos quais quatro eram teses e seis dissertações.

Em seguida, as maiores notas na CAPES pertencem às universidades federais do Paraná e do Rio Grande do Sul. Vale ressaltar que a biblioteca digital da UFPR ${ }^{2}$ apresentou um problema semelhante à da USP, tendo-se optado por pesquisar em todo o acervo para aumentar a gama de resultados apresentados. A partir disso, a palavra-chave "fair play" rendeu 17 trabalhos selecionados de 45 apresentados, "jogo limpo", apenas um trabalho inédito de 26, "espírito esportivo", três inéditos de 24, e "racismo", sete inéditos de 617 apresentados; totalizando, assim, 28 trabalhos de pós-graduação, dos quais cinco teses e 23 dissertações.

O acervo de Ciências do Movimento Humano da Lume, biblioteca digital da UFRGS ${ }^{3}$, por sua vez, teve o maior número de trabalhos encontrados: um total de 74, sendo 21 teses e 53 dissertações. Dentre eles, para a palavra-chave "fair play" se selecionou 23 trabalhos de 28 apresentados, para "jogo limpo", 32 de 46, para "espírito esportivo", apenas seis de 156, e para "racismo", 13 de 32.

Os últimos Programas de Pós-Graduação de Educação Física, com nota maior que quatro na CAPES, representam atualmente as universidades UFV, UFSC, UFMG e UNESP/Rio Claro, sendo que para esta última, não foi encontrado nenhum trabalho relevante ao presente estudo. $\mathrm{Na}$ biblioteca digital de teses e dissertações da UFV4, a coleção de Educação Física apresentou dois trabalhos relevantes de dois apresentados para a palavra-chave "fair play", nenhum resultado inédito para as palavras-chave “jogo limpo" e "espírito esportivo" e apenas um trabalho apresentados e selecionado para "racismo", resultando três dissertações e nenhuma tese.

No Repositório Institucional da UFSC de teses e dissertações ${ }^{5}$ dois Programas de PósGraduação em Educação Física foram pesquisados, um com 60 resultados e outro com 369, sendo que ambos foram utilizados para busca, mas apenas o segundo forneceu resultado. Neste, "fair play" rendeu cinco trabalhos relevantes dentre cinco apresentados, "jogo limpo" não proveu resultados, "espírito esportivo" rendeu dois selecionados de dois apresentados e "racismo", oito de 12. Com isso, elegeu-se um total de 15 trabalhos, sendo que todos são dissertações.

Por fim, na biblioteca digital da UFMG foram identificados dois programas de PósGraduação relevantes à presente pesquisa. No primeiro, em Educação Física': "fair play" e "racismo"

\footnotetext{
${ }^{2} \mathrm{https://acervodigital.ufpr.br/handle/1884/284}$

${ }_{3}^{3} \mathrm{http://www.lume.ufrgs.br/handle/10183/27}$

${ }^{4}$ http://www.locus.ufv.br/handle/123456789/187

${ }_{5}^{5}$ https://repositorio.ufsc.br/handle/123456789/74645

${ }^{6}$ http://www.bibliotecadigital.ufmg.br/dspace/handle/1843/627
} 
não tiveram resultado, enquanto "espírito esportivo" não proveu trabalho para 14 apresentados e "jogo limpo" rendeu três de 16 apresentados. Já para o segundo, Estudos do Lazer7: "fair play" e "racismo" também não apresentaram resultados, enquanto "jogo limpo" teve um trabalho selecionado de um total de dois apresentados e "espírito esportivo", um apresentado e selecionado. Para a biblioteca digital da UFMG, portanto, foram selecionados cinco trabalhos, sendo duas teses e três dissertações.

Tabela 1 - Número de trabalhos encontrados e selecionados para cada palavra-chave e número total disponível na biblioteca digital de cada universidade

\begin{tabular}{|c|c|c|c|c|c|c|c|c|c|c|}
\hline & \multicolumn{2}{|c|}{ "fair play" } & \multicolumn{2}{|c|}{ "jogo limpo" } & \multicolumn{2}{|c|}{ "espírito esportivo" } & \multicolumn{2}{|c|}{ "racismo" } & \multicolumn{2}{|c|}{ Total } \\
\hline & $\begin{array}{c}\text { Encontrad } \\
0\end{array}$ & $\begin{array}{c}\text { Selecionad } \\
0\end{array}$ & $\begin{array}{c}\text { Encontrad } \\
0\end{array}$ & $\begin{array}{c}\text { Selecionad } \\
0\end{array}$ & $\begin{array}{c}\text { Encontrad } \\
0\end{array}$ & Selecionado & $\begin{array}{c}\text { Encontrad } \\
0\end{array}$ & $\begin{array}{c}\text { Selecionad } \\
0\end{array}$ & $\begin{array}{c}\text { Encontrad } \\
0\end{array}$ & Selecionado \\
\hline USP & 111 & 7 & 51 & 0 & 40 & 2 & 80 & 1 & 282 & 10 \\
\hline UFPR & 45 & 17 & 26 & 1 & 24 & 3 & 617 & 7 & 712 & 28 \\
\hline UFRGS & 28 & 23 & 46 & 32 & 156 & 6 & 32 & 13 & 262 & 74 \\
\hline $\begin{array}{l}\text { UNESP- } \\
\text { RC }\end{array}$ & - & & - & & - & & - & & 0 & 0 \\
\hline UFV & 2 & 2 & 1 & 0 & 1 & 0 & 1 & 1 & 5 & 3 \\
\hline UFSC & 5 & 5 & 3 & 0 & 2 & 2 & 12 & 8 & 22 & 15 \\
\hline \multirow[t]{2}{*}{ UFMG } & 0 & 0 & 18 & 4 & 15 & 1 & 0 & 0 & 33 & 5 \\
\hline & & & & & & & & Total & 1316 & 135 \\
\hline
\end{tabular}

Algumas hipóteses foram levantadas para procurar explicar os motivos que levaram a uma redução de aproximadamente $90 \%$ dos trabalhos encontrados para as teses e dissertações que passaram pela primeira triagem (Tabela 1). O primeiro deles, já mencionado anteriormente, se refere aos problemas nos sistemas de buscas em algumas plataformas, que levaram à necessidade de expandir a busca para além dos Programas de Pós-Graduação de Educação Física e Esportes e abranger todos os programas disponíveis nas bibliotecas digitais das duas universidades. Os termos "fair play" e "racismo", por exemplo, são utilizados por muitas outras áreas do conhecimento, como Direito e Sociologia, trazendo resultados que fugiam dos Programas de Pós-Graduação de Educação Física e Esporte e que precisaram ser descartados. Cabe também ressaltar que muitas teses e dissertações referentes ao âmbito esportivo também são produzidas em outros Programas de PósGraduação, como os de Educação, Sociologia e História. No caso da USP e da UFPR, foram encontradas algumas teses e dissertações produzidas nesses programas que se utilizaram do termo "espírito esportivo". Estes trabalhos, no entanto, acabaram não correspondendo aos critérios de inclusão estabelecidos na metodologia da pesquisa. Esta, portanto, pode representar uma das limitações para a presente pesquisa, pois o objetivo foi mapear o Estado da Arte da temática em questão dentro exclusivamente dos Programas de Pós-Graduação de Educação Física e Esportes.

\footnotetext{
${ }^{7}$ http://www.bibliotecadigital.ufmg.br/dspace/handle/1843/25754
} 
Há ainda duas outras hipóteses que podem ter contribuído para a considerável redução dos trabalhos selecionados na primeira triagem. Primeiramente, o termo "racismo" e "fair play", mesmo considerando apenas trabalhos da área da Educação Física, são usado de forma bastante ampla, muitas vezes em uma linguagem informal (não acadêmica) ou apenas como uma referência que não corresponde de fato à temática ou aos conceitos propriamente ditos. Em segundo lugar, foi possível perceber uma proximidade do tema racismo com outros temas abordados por teses e dissertações, como gênero e sexualidade, o que fez com que alguns trabalhos fossem encontrados nas buscas, mas desconsiderados após a primeira triagem por não tratarem diretamente do tema racismo.

Gráfico 1 - Número de teses e dissertações selecionadas de acordo com o ano de publicação

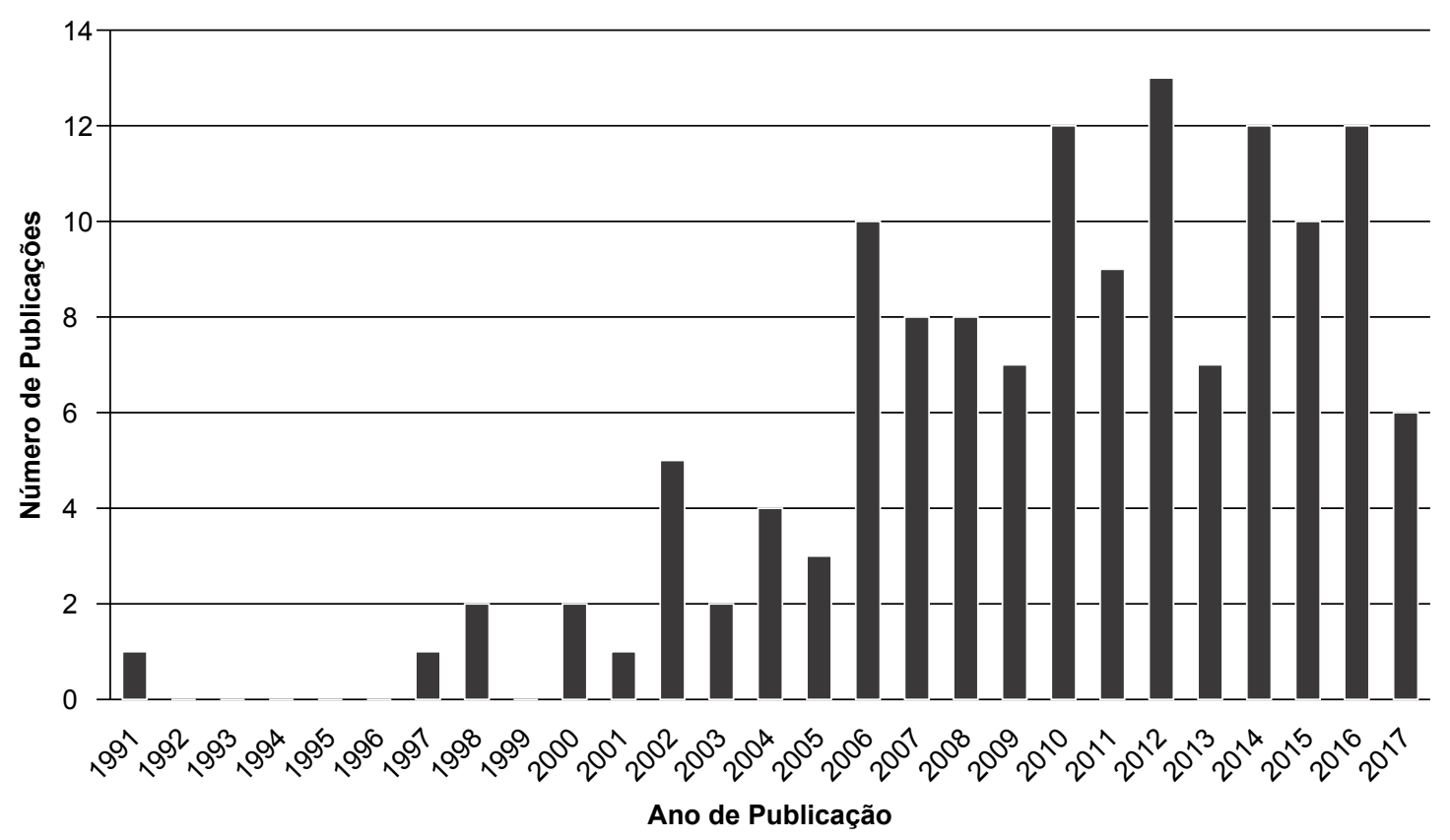

Esses 135 textos selecionados abrangem o período entre os anos 1991 e 2017, sendo que seis deles foram publicados na última década do século XX, 60 na primeira década deste século e os outros 69 até o ano de 2017 (Figura 1). Esse período relativamente recente, assim como o progressivo aumento no número de teses e dissertação, provavelmente está relacionado com a também recente implantação dos Programas de Pós-Graduação de Educação Física no Brasil, em meados da década de 70, e seu expressivo crescimento nas três últimas décadas (KOKOBUN, 2003). É importante destacar ainda que nesse processo houve uma disparidade no crescimento das subáreas da Educação Física em seus Programas de Pós-Graduação, pois as áreas de Exatas e Biológicas apresentaram uma expansão mais significativa do que as de Sociocultural e Pedagógica devido a fatores de avaliação e estruturação da educação física dentro da área 21 da CAPES (BETTI et al., 2014; LAZZAROTTI et al., 2018). De todo modo, é perceptível que a produção e 
digitalização de teses e dissertações vêm aumentando com o tempo, o que explica o aumento no número de textos selecionados com o passar dos anos.

Após a primeira seleção, foi realizado o procedimento de leitura, descrito na metodologia, de um total de 135 trabalhos, dentre os quais 32 eram teses e 103 eram dissertações. Posteriormente a realização dos três passos de aprofundamento da leitura de cada texto e a realização do fichamento de cada um deles, foi realizado um segundo processo de seleção, a fim de separar as teses e dissertações mais relevantes para o presente estudo. Com isso, apenas 15 fichas (cinco de tese e dez de dissertações) foram consideradas importantes ao que está sendo proposto pela pesquisa, sendo que oito foram levantadas na UFPR, quatro na UFRGS, duas na USP e uma na UFV (Tabela 2).

Tabela 2 - Número de teses e dissertações selecionadas e consideradas relevantes para a análise qualitativa

\begin{tabular}{ccccccc} 
& \multicolumn{3}{c}{ Selecionados } & & Relevantes \\
\hline & Teses & Dissertações & Total & Teses & Dissertações & Total \\
\hline USP & 4 & 6 & 10 & 1 & 1 & 2 \\
UFPR & 5 & 23 & 28 & 3 & 5 & 8 \\
UFRGS & 21 & 53 & 74 & 1 & 3 & 4 \\
UNESP-RC & - & & 0 & - & & 0 \\
UFV & 0 & 3 & 3 & 0 & 1 & 1 \\
UFSC & 0 & 15 & 17 & 0 & 0 & 0 \\
UFMG & 2 & 3 & 5 & - & & 0 \\
\hline Total & 32 & 103 & 135 & 5 & 10 & 15
\end{tabular}

Como pode ser observado na Tabela 2, houve uma redução significativa durante a segunda seleção, de aproximadamente $89 \%$. Isso provavelmente se deve aos motivos já apresentados anteriormente, como o amplo uso das palavras "fair play" e "racismo" em diferentes contextos, assim como a proximidade da temática com outras ligadas à diversidade, mostrando que a primeira triagem, de fato, não foi eficiente nesse sentido. O motivo mais comum, no entanto, foi a concentração de uma tese ou dissertação em apenas uma das temáticas aqui estudada, tratando ou do FP ou do racismo separadamente, não permitindo encontrar uma relação evidente entre ambos.

Dentre esses 15 trabalhos considerados mais relevantes, mais da metade deles foram encontrados no acervo da UFPR. Isso pode estar relacionado à presença da linha de pesquisa em Esporte, Lazer e Sociedade dentro de seu programa de Pós-Graduação de Educação Física ${ }^{8}$, dentro dos quais os projetos de pesquisa conseguem abranger as temáticas aqui abordadas. Vale ressaltar que seis dessas oito produções foram orientadas por dois pesquisadores, Fernando Marinho Mezzadri e Wanderley Marchi Júnior, mostrando uma representatividade significativa da produção sociocultural da Educação Física dentro da UFPR.

\section{Análises Qualitativas}

\footnotetext{
${ }^{8} \mathrm{http}: / /$ www.pgedf.ufpr.br/sociologiael.htm
} 
Tabela 3 - Teses e dissertações selecionadas com mais relevantes após o fichamento dos 135 trabalhos inicialmente levantados

\begin{tabular}{|c|c|c|c|c|c|}
\hline Autor(a) & $\begin{array}{c}\text { Orientador(a } \\
\text { ) }\end{array}$ & Título & Texto & $\begin{array}{l}\text { Universidad } \\
\text { e }\end{array}$ & Ano \\
\hline $\begin{array}{l}\text { Silvia Regina } \\
\text { Godinho } \\
\text { Bauler }\end{array}$ & $\begin{array}{l}\text { Marco Paulo } \\
\text { Stigger }\end{array}$ & $\begin{array}{l}\text { O futebol faz rolar mais do que uma bola: um estudo } \\
\text { sobre os significados do futebol numa periferia urbana }\end{array}$ & Dissertação & UFRGS & 2004 \\
\hline $\begin{array}{l}\text { Marzo } \\
\text { Vargas dos } \\
\text { Santos }\end{array}$ & $\begin{array}{l}\text { Vicente } \\
\text { Molina Neto }\end{array}$ & $\begin{array}{l}\text { O estudante negro na cultura estudantil e na educação } \\
\text { física e escolar }\end{array}$ & Dissertação & UFRGS & 2007 \\
\hline $\begin{array}{l}\text { Bruno } \\
\text { Boschilia }\end{array}$ & $\begin{array}{l}\text { Wanderley } \\
\text { Marchi Júnior }\end{array}$ & $\begin{array}{c}\text { Futebol e violência em campo: análise das } \\
\text { interdependências entre árbitros, regras e instituições } \\
\text { esportivas }\end{array}$ & Dissertação & UFPR & 2008 \\
\hline $\begin{array}{l}\text { Flávio Py } \\
\text { Mariante } \\
\text { Neto }\end{array}$ & $\begin{array}{l}\text { Marco Paulo } \\
\text { Stigger }\end{array}$ & $\begin{array}{c}\text { Da academia de boxe ao boxe da academia: um } \\
\text { estudo etnográfico }\end{array}$ & Dissertação & UFRGS & 2010 \\
\hline $\begin{array}{l}\text { Saulo } \\
\text { Esteves de } \\
\text { Camargo } \\
\text { Prestes }\end{array}$ & $\begin{array}{l}\text { Fernando } \\
\text { Marinho } \\
\text { Mezzadri }\end{array}$ & $\begin{array}{l}\text { O estatuto de defesa do torcedor e suas implicações } \\
\text { na relação de oferta e demanda no futebol brasileiro: o } \\
\text { caso do Coritibs Foot Ball Club }\end{array}$ & Dissertação & UFPR & 2010 \\
\hline $\begin{array}{l}\text { Ana Paula } \\
\text { Cabral Bonin }\end{array}$ & $\begin{array}{l}\text { Fernando } \\
\text { Marinho } \\
\text { Mezzadri }\end{array}$ & $\begin{array}{c}\text { Ações públicas e privadas destinadas ao combate a } \\
\text { violência no futebol: o caso do jogo entre Coritiba Foot } \\
\text { Ball Club e Fluminense Foot Ball Club }\end{array}$ & Dissertação & UFPR & 2011 \\
\hline $\begin{array}{l}\text { Roberto } \\
\text { Andaki } \\
\text { Junior }\end{array}$ & $\begin{array}{l}\text { José Geraldo } \\
\text { do Carmo } \\
\text { Salles }\end{array}$ & $\begin{array}{l}\text { Fair Play: instrumentos para avaliação e as } \\
\text { orientações desses valores no comportamento de } \\
\text { jovens atletas }\end{array}$ & Dissertação & UFV & 2012 \\
\hline $\begin{array}{l}\text { Riqueldi } \\
\text { Straub Lise }\end{array}$ & $\begin{array}{l}\text { André } \\
\text { Mendes } \\
\text { Capraro }\end{array}$ & $\begin{array}{l}\text { Entre direitos, ceintures avant, chaves de braço e } \\
\text { rabos de arraia: os primórdios dos combates } \\
\text { intermodais na cidade do Rio de Janeiro (19009-1929) }\end{array}$ & Dissertação & UFPR & 2014 \\
\hline $\begin{array}{l}\text { Juliano de } \\
\text { Souza }\end{array}$ & $\begin{array}{l}\text { Wanderley } \\
\text { Marchi Júnior }\end{array}$ & $\begin{array}{c}\text { O “esporte das multidões" no Brasil: entre o contexto } \\
\text { de ação futebolístico e a negociação mimética dos } \\
\text { conflitos sociais }\end{array}$ & Tese & UFPR & 2014 \\
\hline $\begin{array}{l}\text { Bárbara } \\
\text { Schausteck } \\
\text { de Almeida }\end{array}$ & $\begin{array}{l}\text { Wanderley } \\
\text { Marchi Júnior }\end{array}$ & $\begin{array}{l}\text { Altius, citius, fortius... ditius? Lógicas e estratégias do } \\
\text { Comitê Olímpico Internacional, Comitê de Candidatura } \\
\text { e Governo Brasileiro na candidatura e escolha dos } \\
\text { Jogos Olímpicos e Paralímpicos Rio } 2016\end{array}$ & Tese & UFPR & 2015 \\
\hline $\begin{array}{l}\text { Aline } \\
\text { Dessupoio } \\
\text { Chaves }\end{array}$ & $\begin{array}{l}\text { Osvaldo Luiz } \\
\text { Ferraz }\end{array}$ & $\begin{array}{c}\text { O clima motivacional nas práticas pedagógicas do } \\
\text { esporte educacional }\end{array}$ & Tese & USP & 2015 \\
\hline $\begin{array}{l}\text { Ana Paula } \\
\text { Prestes de } \\
\text { Souza }\end{array}$ & $\begin{array}{l}\text { Doralice } \\
\text { Lange de } \\
\text { Souza }\end{array}$ & $\begin{array}{l}\text { Cultura esportiva: um possível legado do Jogos } \\
\text { Olímpicos e Paralímpicos Rio 2016? }\end{array}$ & Dissertação & UFPR & 2015 \\
\hline $\begin{array}{l}\text { Luciano } \\
\text { Juchem }\end{array}$ & $\begin{array}{l}\text { Carlos Adelar } \\
\text { Abaide } \\
\text { Balbinotti }\end{array}$ & $\begin{array}{l}\text { Contribuições das competições esportivas para a } \\
\text { formação e educação de crianças e jovens: o caso dos } \\
\text { jogos escolares de Petrolina }\end{array}$ & Tese & UFRGS & 2015 \\
\hline $\begin{array}{l}\text { Ana Paula } \\
\text { Cabral Bonin } \\
\text { Maoski }\end{array}$ & $\begin{array}{l}\text { Fernando } \\
\text { Marinho } \\
\text { Mezzadri }\end{array}$ & $\begin{array}{l}\text { A (des)articulação entre os entes federativos que } \\
\text { promovem o esporte de rendimento no Brasil, no } \\
\text { Paraná e em Curitiba }\end{array}$ & Tese & UFPR & 2016 \\
\hline $\begin{array}{l}\text { José Arthur } \\
\text { Fernandes } \\
\text { Barros }\end{array}$ & $\begin{array}{l}\text { Flávia da } \\
\text { Cunha } \\
\text { Bastos }\end{array}$ & $\begin{array}{l}\text { Estrutura organizacional e das tomadas de decisão em } \\
\text { clubes socioesportivos de São Paulo }\end{array}$ & Dissertação & USP & 2016 \\
\hline
\end{tabular}


Após uma primeira análise quantitativa, as 15 fichas selecionadas foram revisitadas para um aprofundamento nas teses e dissertações com o intuito de estabelecer relações entre elas e compreender melhor o atual Estado da Arte da temática em questão. A Tabela 3 dispõe as cinco teses e dez dissertações em ordem cronológica.

Os trabalhos considerados como mais relevantes se destacaram por permitir o desenvolvimento de alguma ligação entre as duas temáticas ou entre questões adjacentes a elas. A pesquisa que apresentou análises mais extensas e aprofundadas sobre o racismo no esporte foi a tese de Souza (2014). O autor analisa os mecanismos que tornaram o futebol um fenômeno de apelo massivo no Brasil, assim como os significados e funções sociais desempenhadas pela sua prática no país. A pesquisa realiza uma profícua problematização sobre o racismo tanto no futebol quanto na sociedade brasileira. Nesse ponto em específico, o autor descontrói o mito da democracia racial, ao empregar as pesquisas de Florestan Fernandes para pensar o futebol como um local de reforço deste mito em nossa sociedade. Além disso, Souza (2014, p.128) evidencia casos históricos de racismo estrutural dentro da modalidade em questão, na qual jogadores e torcedores negros "procuravam se comportar nos estádios em conformidade com os padrões de etiqueta impostos pelas elites brancas".

A partir da tese de Souza podem ser estabelecidos paralelos com os demais trabalhos aqui analisados, uma vez que a profundidade dada pelo autor ao racismo dentro da sociedade e do esporte brasileiro permite entender melhor a relação dessas teses e dissertações com o presente trabalho. Em um primeiro momento, nota-se que muitos desses textos também são voltados para a modalidade específica do futebol, buscando analisar casos de violência entre torcidas e a inserção racial ao longo do século XX (BAULER, 2004; BOSCHILIA, 2008; PRESTES, 2010; BONIN, 2011, BARROS, 2016).

A dissertação de Barros (2016) descreve os processos de gestão da área esportiva de seis clubes sócio-esportivos da cidade de São Paulo. Ainda que tenha um objetivo central não esteja ligado com o racismo, há uma passagem na qual o autor ressalta que para se analisar a história esportiva brasileira é necessário levar em conta a influência do regime escravocrata conservado até o final do século XIX.

Boschilia (2008) analisa a violência no futebol a partir da perspectiva dos árbitros, cuja subjetividade da interpretação é combustível para as discórdias surgidas em partidas da modalidade. Aborda as campanhas de FP realizadas pela Federação Internacional de Futebol (FIFA) como uma forma de construir uma imagem mais sadia para a modalidade e atrair novos torcedores e investidores. Assim como Souza (2014), o autor também traz em sua dissertação alguns casos notórios de racismo no futebol, tais como a intriga entre o brasileiro Edinaldo Batista (conhecido 
como Grafite) e o argentino Leandro Desábato, em 2005, além de destacar o racismo como "a primeira forma de violência presente no futebol brasileiro" (p.155).

Bauler (2004), ao estudar os significados do futebol em uma periferia urbana em sua dissertação, alerta para o fato da imprensa brasileira frequentemente reforçar o mito da democracia racial ao discorrer sobre o futebol, incorrendo na afirmativa de que a miscigenação racial esteve presente no desenvolvimento do futebol ao longo do século XX e foi responsável pela criação de uma maneira particular de jogá-lo no país - popularmente conhecido como "futebol arte".

Prestes (2010) se propõe a analisar a implicação da implementação do Estatuto de Defesa do Torcedor na relação estabelecida entre o Coritiba Foot Ball Club e seus torcedores. Ao se referir a FIFA, analisa como pressões sociais e políticas tem provocado mudanças nas suas estruturas e nos seus posicionamentos nos últimos anos. A violência entre torcidas e o Estatuto de Defesa do Torcedor são foco também da dissertação de Bonin (2011), na qual as motivações do conflito entre as torcidas do Coritiba Foot Ball Club e do Fluminense Football Club, em 2009, são analisadas para se pensar ações públicas e privadas destinadas ao seu combate. Ambos os autores apontam como tais casos de violência dentre as torcidas de equipes de futebol podem ter motivações étnico-raciais.

Para além do futebol, as pesquisas de Lise (2009) e Mariante Neto (2010) se concentraram nas modalidades esportivas de combate. Como estruturado por Souza (2014), o racismo não se fez presente apenas no futebol, mas sim em todo o esporte brasileiro, a partir disso se faz necessário entender quais foram as principais influências para que negros encontrassem seu espaço dentro do campo esportivo. Segundo Lise (2009), é possível observar na luta um caminho facilitador para a inserção étnico-racial, uma vez que as primeiras modalidades a se disseminarem pelo país tinham caráter elitista, como o turfe e o remo (LISE, 2009).

Lise (2009) busca compreender como as lutas foram retratadas nos periódicos da cidade do Rio de Janeiro, entre os anos de 1909 e 1929. Problematiza em sua dissertação o racismo inscrito na criminalização da capoeira no século XIX e o retratos produzidos pelos periódicos do início do século XX dela enquanto elemento de desordem social. O autor apresenta os discursos instituídos pela imprensa carioca que visavam suprimir os costumes e tradições da população negra, característicos do racismo estrutural, e aqueles que, por outro lado, procuravam legitimar a capoeira como integrante da identidade nacional.

Mariante Neto (2010) aborda especificamente a modalidade do boxe, porém seu foco é na compreensão dos elementos simbólicos presentes na prática da luta dentro das academias de fitness a partir de um estudo etnográfico. Assim como Lise (2009), o autor cita a importância das lutas como símbolos de visibilidade social de grupos oprimidos. Narra a trajetória de Muhammad Ali, pugilista norte-americano que se destacou tanto por suas habilidades como atleta quanto por sua 
representatividade no movimento negro, de modo a explorar os imaginários sociais construídos para a modalidade do boxe.

Ao se pensar o esporte de alto rendimento, como vem sendo abordado até o presente momento, é importante discutir também as políticas públicas concebidas para a sua organização e desenvolvimento. Isso se justifica nesta pesquisa por ter sido estabelecida uma relação entre o racismo estruturado na sociedade brasileira e os obstáculos enfrentados pelos afrodescendentes em se inserirem no campo esportivo (SOUZA, 2014).

Maoski (2016), por exemplo, aborda a estruturação e as ações das instâncias promotoras do esporte de alto rendimento no Brasil, no Paraná e no município de Curitiba, identificando ainda a necessidade de se melhorar a articulação entre elas para a consolidação do Sistema Nacional de Esporte brasileiro. Maoski (2016) não chega a abordar o tema do racismo, mas a sua pesquisa permite estabelecer uma correlação entre as mudanças sócio-políticas do país e as políticas de regimento do esporte de alto rendimento, o que, por sua vez, poderia repercutir-se na repressão de atitudes racistas. A autora alerta, no entanto, para a dificuldade de implementação de uma gestão compartilhada entre a União, estados e municípios, uma vez que não existem mecanismos que estimulem a cooperação entre os mesmos.

Almeida (2015), por sua vez, realiza um estudo sobre a candidatura do Rio de Janeiro aos Jogos Olímpicos e Paralímpicos de 2016 e buscar identificar as estratégias adotadas pelo Comitê Olímpico Internacional, pelo comitê de candidatura e pelo governo brasileiro durante esse processo. A autora analisa que a apresentação do Brasil como candidato a sede dos Jogos Olímpicos de 2016 se utilizou do mito da democracia racial para criar a imagem de um país miscigenado e harmonioso.

Para além do esporte profissional, foram levantados também pesquisas que abordaram o FP e o racismo no contexto da Educação Física escolar (SANTOS, 2007; ANDAKI JUNIOR, 2012; CHAVES, 2015; SOUZA, 2015; JUCHEM, 2015). Todos os trabalhos partiram da premissa que o racismo se estruturou na sociedade brasileira ao longo do século XX, permeando seus mais diversos campos, como observado por Souza (2014).

Nesse sentido, se insere a dissertação de Santos (2007), na qual busca compreender como estudantes negros da Rede Municipal de Ensino de Porto Alegre se constituem nas interações sociais e como essas construções se manifestam na cultura estudantil e na Educação Física escolar. A partir de pesquisa etnográfica, autor conclui que os estudantes tendem a naturalizar a posição de inferioridade relegada ao negro em nossa sociedade, demonstrando a necessidade de se trabalhar questões pertinente à temática no ambiente escolar.

Já Andaki Junior (2012) aponta a baixa produção acadêmica sobre a temática do FP na Educação Física brasileira, reforçando os dados quantitativos levantados pela presente pesquisa. A 
dissertação promove a adaptação transcultural do instrumento The Multidimensional Sportspersonship Orientations Scale, o qual avalia a orientação de escolares em aderir a conceitos e valores relacionados ao FP. O autor ressalta a importância da prática esportiva ser adaptada ao ambiente escolar para que o FP seja trabalhado com os estudantes.

Chaves (2015) estuda as Práticas Esportivas Educacionais, método pedagógico cujo obtivo é motivar os alunos e estimular a sua autonomia, a sua tomada de decisão e o prazer. A autora explora, em alguns momentos, a oportunidade de se trabalhar dentro do ambiente escolar valores importantes para a formação voltada para a cidadania, tais como a socialização, inclusão e respeito, realçando a importância da Educação Física nesse processo.

Souza $(2015$, p.65) também reforça a importância da Educação Física escolar na formação de cidadãos e atletas com atitudes éticas: “outra questão que merece atenção dos professores de Educação Física escolar e que deve ser debatida são os temas relacionados, por exemplo, a gênero, ao racismo e ao doping no esporte". A dissertação teve por objetivo entrevistar pesquisadores de distintas áreas das Ciências do Esporte em relação à influência da realização dos Jogos Olímpicos Rio 2016 para o desenvolvimento da cultura esportiva no país partindo de três perspectivas: mídia, escola e Estado. É interessante notar que a autora critica a prevalência do modelo de esporte de alto rendimento no âmbito escolar, assim como Andaki Junior (2012), fato esse que dificultaria a formação cidadã dos estudantes.

Juchem (2014) parte de outro pressuposto ao investigar a contribuição dos Jogos Escolares de Petrolina para a formação e educação de seus participantes. Apesar de não abordar o racismo, a sua tese apresenta a competição escolar como um espaço importante para a construção de valores como o respeito ao adversário e tolerância. Aborda ainda as consequências positivas da competição para a vida pessoal das crianças e adolescentes envolvidos com os Jogos Escolares de Petrolina, como, por exemplo, a redução do abandono escolar, e observa a importância de se trabalhar valores éticos e morais dentro das competições escolares.

\section{CONSIDERAÇÕES FINAIS}

O principal fator levantado para a pequena quantidade de teses e dissertações consideradas relevantes, $11 \%$ das selecionadas, é o de que poucas trabalham FP e racismo de forma concomitante. Mesmo dentre os 15 trabalhos analisados, a relação entre as duas temáticas não foi central, aparecendo apenas em poucas e curtas passagens de algumas pesquisas. 
$\mathrm{Na}$ análise das teses e dissertações consideradas mais relevantes identificou-se que a maioria delas aborda as modalidades esportivas do futebol e das lutas. Em sua maioria analisam o fenômeno esportivo em nosso país a partir da perspectiva do racismo estrutural, rechaçando o mito da democracia racial. Algumas destacam a importância dessas modalidades esportivas para a inserção e a afirmação do negro em nossa sociedade, sobretudo a capoeira e do boxe. Não deixam, contudo, de apresentar os desafios que tais modalidades tiveram e continuam a ter para se afirmarem socialmente em nosso país devido ao racismo. No caso específico do futebol, há uma parcela significativa de trabalhos que abordaram a violência entre torcidas e que destacaram as motivações étnico-raciais presentes nessas situações. A participação da FIFA na promoção do FP e no combate ao racismo também é citada nesses casos e é analisada a partir das pressões sociais e políticas para que a entidade aborde tais temas, assim como pelo fato de tais temas poderem atrair novos investidores para a modalidade.

Uma parte considerável das teses e dissertações analisadas apresenta a importância de se tratar o FP na Educação Física escolar e em competições escolares. Nelas é levantada a relevância de se trabalhar questões éticas no esporte desde cedo, tais como a inclusão social e racial, para que futuros atletas de alto nível não demonstrem atitudes reprováveis e discriminatórias em suas modalidades, assim como para a formação plena de cidadãos. Apesar de diferenciarem o esporte de alto rendimento do esporte escolar, tais pesquisas não realizam análises críticas sobre a imagem que o Movimento Olímpico Internacional procura construir para si através do FP, das contradições da “educação olímpica” ou dos usos políticos e econômicos do esporte em nossa sociedade.

Por fim, é importante destacar que o levantamento realizado mostra que o FP e o racismo no esporte se configuram como profícuos temas de pesquisa para o campo da Educação Física brasileira, pois abrem possibilidade para uma multiplicidade de análises e problematizações acadêmicas sobre o fenômeno esportivo.

\section{REFERÊNCIAS}

ALMEIDA, Bárbara Schausteck de. Altius, Citius, Fortius... Ditius? Lógicas e estratégias do Comitê Olímpico Internacional, Comitê de Candidatura e Governo Brasileiro na candidatura e escolho dos Jogos Olímpicos e Paralímpicos Rio 2016. 2015. 327f. Tese (Doutorado em Educação Física). Setor de Ciências Biológicas da Universidade Federal do Paraná, Curitiba, 2015.

ANDAKI JUNIOR, Roberto. Fair Play: instrumentos para avaliação e as orientações desses valores no comportamento de jovens atletas. 2012. 83f. Dissertação (Mestrado em Educação Física). Universidade Federal de Viçosa, Viçosa, 2012. 
BARROS, José Arthur Fernandes. Estrutura organizacional e das tomadas de decisão em Clubes Socioesportivos de São Paulo. 2016. 150f. Dissertação (Mestrado em Estudos Socioculturais e Comportamentais da Educação Física e Esporte). Escola de Educação Física e Espore da Universidade de São Paulo, São Paulo, 2016.

BAULER, Silvia Regina Godinho. O futebol faz rolar mais do que uma bola: um estudo sobre os significados do futebol numa periferia urbana. 2004. 124f. Dissertação (Mestrado em Ciências do Movimento Humano). Escola de Educação Física da Universidade Federal do Rio Grande do Sul, Porto Alegre, 2004.

BETTI, Mauro; CARVALHO, Yara Maria de; DAOLIO, Jocimar; PIRES, Giovani De Lorenzi. A avaliação da Educação Física em debate: implicações para a subárea pedagógica e sociocultural. Revista Brasileira de Pós-Graduação, v.1, n.2, p.183-194, nov 2004

BONIN, Ana Paula Cabral. Ações públicas e privadas destinadas ao combate à violência no futebol: o caso do jogo entre Coritiba Foot Ball Club e Fluminense Football Club. 2011. 126f. Dissertação (Mestrado em Educação Física). Setor de Ciências Biológicas da Universidade Federal do Paraná, 2011.

BOSCHILIA, Bruno. Futebol e violência em campo: análise das interdependências entre árbitros, regras e instituições esportivas. 2008. 192f. Dissertação (Mestrado em Educação Física). Setor de Ciências Biológicas da Universidade Federal do Paraná, Curitiba, 2008.

CHAVES, Aline Dessupoio. O clima motivacional nas práticas pedagógicas do esporte educacional. 2015. 171f. Tese (Doutorado em Pedagogia do Movimento Humano). Escola de Educação Física e Esporte da Universidade de São Paulo, São Paulo, 2015.

COMITÊ OLÍMPICO INTERNACIONAL. Carta Olímpica. Lisboa: Instituto Português do Desporto e Juventude, 2011.

FERNANDES, Florestan. A integração do negro na sociedade de classes: o legado da raça branca. 5 ed. São Paulo: Ed. Globo, 2008.

FERREIRA, Norma Sandra de Almeida. As pesquisas denominadas "estado da arte". Educação \& Sociedade, Campinas, v.23, n.79, p.257-272, ago 2002.

GAY, Peter. A experiência burguesa: da Rainha Vitória a Freud. São Paulo: Companhia das Letras, 1995, v.3.

GOIS JÚNIOR, Edivaldo. O esporte e a modernidade em São Paulo: práticas corporais no fim do século XIX e início do XX. Movimento, Porto Alegre, v.19, n.4, p.95-117, out/dez 2013.

KOKOBUN, Eduardo. Pós-Graduação em Educação Física no Brasil: indicadores objetivos dos desafios e das perspectivas. Revista Brasileira de Ciências do Esporte, Campinas, v.24, n.2, p.926, jan 2003.

JUCHEM, Luciano. Contribuições das competições esportivas para a formação e educação de crianças e jovens: o caso dos Jogos Escolares de Petrolina. 2015. 255f. Tese (Doutorado em Ciências do Movimento Humano). Escola de Educação Física da Universidade Federal do Rio Grande do Sul, Porto Alegre, 2015. 
LAZZAROTTI FILHO, Ari; MASCARENHAS, Fernando; STIGGER, Marco Paulo; SILVEIRA, Raquel da; SILVA, Ana Márcia. Tendências no campo da educação física brasileira. Análise dos documentos produzidos pela área 21 da Capes. Revista Brasileira de Ciências do Esporte, 2018 (no prelo).

LISE, Riqueldi Straub. Entre direitos, ceintures avant, chaves de braço e rabos de arraia: os primórdios dos combates intermodalidades na cidade do Rio de Janeiro (1909-1929). 2014. 152f. Dissertação (Mestrado em Educação Física). Setor de Ciências Biológicas da Universidade Federal do Paraná, Curitiba, 2014.

MAOSKI, Ana Paula Cabral Bonin. A (des)articulação entre os entes federativos que promovem o esporte de rendimento no Brasil, no Paraná e em Curitiba. 2016. 446f. Tese (Doutorado em Educação Física). Setor de Ciências Biológicas da Universidade Federal do Paraná, Curitiba, 2016.

MARCONI, Marina de Andrade; LAKATOS, Eva Maria. Fundamentos de metodologia científica. 5.ed. São Paulo: Ed. Atlas, 2003.

MARIANTE NETO, Flávio Py. Da academia de boxe ao boxe de academia: um estudo etnográfico. 2010. 125f. Dissertação (Mestrado em Ciências do Movimento Humano). Escola de Educação Física da Universidade Federal do Rio Grande do Sul, Porto Alegre, 2010.

MEINBERG, Eckhard. Ética Olímpica: Algumas características e perspectivas. In: RUBIO, Kátia; REPPOLD FILHO, Alberto; TODT, Nelson; MESQUITA, Roberto (Org.). Ética \& Compromisso Social nos Estudos Olímpicos. Porto Alegre: EDIPUCRS, 2007.

ORGANIZAÇÃO DAS NAÇÕES UNIDAS. Declaração Universal dos Direitos Humanos. 1948.

PRESTES, Saulo Esteves de Camargo. O Estatuto de Defesa do Torcedor e suas implicações na relação de oferta e demanda no futebol brasileiro: o caso do Coritiba Foot Ball Club. 2010. 208f. Dissertação (Mestrado em Educação Física). Setor de Ciências Biológicas da Universidade Federal do Paraná, Curitiba., 2010

PRODANOV, Cleber Cristiano; FREITAS, Ernani Cesar de. Metodologia do trabalho científico: métodos e técnicas de pesquisa e do trabalho acadêmico. 2.ed. Novo Hamburgo: Ed. Feevale, 2013.

SANTOS, Antônio Roberto Rocha. Espírito Esportivo - Fair Play e a prática de esportes. Revista Mackenzie de Educação Física e Esporte, São Paulo, v.4, n.4, p.13-28, jun/ago 2005.

SANTOS, Marzo Vargas dos. O estudante negro na cultura estudantil e na educação física escolar. 2007. 240f. Dissertação (Mestrado em Ciências do Movimento Humano). Escola de Educação Física da Universidade Federal do Rio Grande do Sul, Porto Alegre, 2007.

SKIDMORE, Thomas Elliot. Preto no branco: raça e nacionalidade no pensamento brasileiro (1870-1930). São Paulo: Companhia das Letras, 2012.

SOUZA, A. P. P. Cultura esportiva: um possível legado dos Jogos Olímpicos e Paralímpicos Rio 2016? 2015. 93f. Dissertação (Mestrado em Educação Física). Setor de Ciências Biológicas da Universidade Federal do Paraná, Curitiba, 2015. 
SOUZA, Juliano de. O "Esporte das Multidões" no Brasil: entre o contexto de ação futebolístico e a negociação mimética dos conflitos sociais. 2014. 433f. Tese (Doutorado em Educação Física). Setor de Ciências Biológicas da Universidade Federal do Paraná, Curitiba, 2014.

TAVARES, Otávio. Fair-play. In: GONZÁLES, Fernando Jaime; FENSTERSEIFER, Paulo Evaldo. (Org.). Dicionário crítico de educação física. 3.ed. rev. ampl. Ijuí: Ed. Unijuí, 2014.

VIGARELLO, Georges; HOLT, Richard. O corpo trabalhado: ginastas e esportistas no século XIX. In: CORBIN, Alain.; COURTINE, Jean-Jaques; VIGARELLO, Georges. (Org.). História do Corpo: da Revolução à Grande Guerra. Tradução de CLASEN, J. A.; KREUCH, J. B. v.2. 3.ed. Petrópolis: Ed. Vozes, 2008.

ZUBAIDA, Sami. Racismo. In: OUTHWAITE, William; BOTTOMORE, Tom. (Org.). Dicionário do pensamento social do Século XX. Rio de Janeiro: Jorge Zahar Ed., 1996.

\section{NOTAS DE AUTOR}

\section{AGRADECIMENTOS}

João Vitor Busquim Braga (in memoriam)

\section{CONTRIBUIÇÃO DE AUTORIA}

Concepção do manuscrito: J. V. B. Braga, K. K. Oshima, A. Dalben

Coleta de dados: J. V. B. Braga, K. K. Oshima

Análise de dados: J. V. B. Braga, K. K. Oshima

Discussão dos resultados: J. V. B. Braga, K. K. Oshima

Produção do texto: J. V. B. Braga, K. K. Oshima, A. Dalben

Revisão e aprovação: A. Dalben

FINANCIAMENTO - Não se aplica.

CONSENTIMENTO DE USO DE IMAGEM - Não se aplica.

APROVAÇÃO DE COMITÊ DE ÉTICA EM PESQUISA - Não se aplica.

CONFLITO DE INTERESSES - Não há conflito de interesses.

\section{LICENÇA DE USO}

Os autores cedem à Motrivivência - ISSN 2175-8042 os direitos exclusivos de primeira publicação, com o trabalho simultaneamente licenciado sob a Licença Creative Commons Attribution Non-Comercial ShareAlike (CC BY-NC SA) 4.0 International. Estra licença permite que terceiros remixem, adaptem e criem a partir do trabalho publicado, desde que para fins não comerciais, atribuindo o devido crédito de autoria e publicação inicial neste periódico desde que adotem a mesma licença, compartilhar igual. Os autores têm autorização para assumir contratos adicionais separadamente, para distribuição não exclusiva da versão do trabalho publicada neste periódico (ex.: publicar em repositório institucional, em site pessoal, publicar uma tradução, ou 
como capítulo de livro), com reconhecimento de autoria e publicação inicial neste periódico, desde que para fins não comerciais e compartilhar com a mesma licença.

\section{PUBLISHER}

Universidade Federal de Santa Catarina. Programa de Pós-Graduação em Educação Física. LaboMídia - Laboratório e Observatório da Mídia Esportiva. Publicado no Portal de Periódicos UFSC. As ideias expressadas neste artigo são de responsabilidade de seus autores, não representando, necessariamente, a opinião dos editores ou da universidade.

\section{EDITORES}

Mauricio Roberto da Silva, Giovani De Lorenzi Pires, Rogério Santos Pereira.

\section{HISTÓRICO}

Recebido em: 28 de julho de 2018.

Aprovado em: 25 de abril de 2019. 